ПРОДУКТИВНОСТЬ И КАЧЕСТВЕННЫЕ ПОКАЗАТЕЛИ ИНКУБАЦИОННЫХ ЯИЦ КУР РОДИТЕЛЬСКОГО СТАДА КРОССА РОСС 308 ПРИ ИСПОЛЬЗОВАНИИ ПРЕПАРАТА «ЭСИД-ПАК-4-УЭЙ»

\title{
PRODUCTIVITY AND QUALITY INDICATORS OF HATCHING EGGS OF CHICKENS OF THE PARENT HERD OF CROSS ROSS 308 WHEN USING THE DRUG «ACID-PAK-4-WAY»
}

${ }^{1}$ Ткачева И.В., кандидат сельскохозяйственных наук

${ }^{2}$ Комарова 3.Б., доктор сельскохозяйственных наук, доцент

${ }^{2}$ Kротова O.E., кандидат сельскохозяйственных наук

${ }^{3}$ Ножник Д.Н., кандидат сельскохозяйственных наук

${ }^{I}$ Tkacheva I.V., candidate of agricultural sciences

${ }^{2}$ Komarova Z.B., doctor of agricultural sciences, associate professor

${ }^{2}$ Krotova O.E., candidate of agricultural sciences

${ }^{3}$ Nozhnik D.N., candidate of agricultural sciences

${ }^{1}$ Донской государственный аграрный университет, пос. Персиановский

${ }^{2}$ Поволжский научно-исследовательский институт производства и переработки мясомолочной продукции, Волгоград

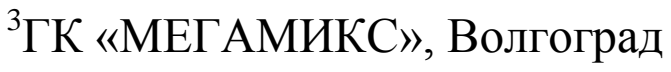

\author{
${ }^{1}$ Don state agrarian university, Persianovskiy \\ ${ }^{2}$ Volga region research institute of manufacture and processing \\ of meat-and-milk production, Volgograd \\ MEGAMIX GC, Volgograd
}

В статье представлены результаты исследований влияния пробиотического препарата «ЭСИД-ПАК-4-УЭЙ» на продуктивность кур родительского стада кросса РОСС 308 и качественные показатели инкубационных яиц. Результаты инкубации яиц показали высокую эффективность изучаемого препарата на вывод здоровых цыплят в опытной группе, который превысил контроль на 3,08\%.

The article presents the results of studies of the impact of probiotic drug «ACID-PAK-4-WAY» on the productivity of the parent herd of cross-chickens ROSS 308 and high-quality incubation eggs. The results of egg incubation showed high efficien- 
cy of the studied preparation for the output of healthy chickens in the experimental group, which exceeded the control by $3.08 \%$.

Ключевые слова: кормление, родительское стадо кросса РОСС 308, инкубационные яйца, морфологические показатели яиц, результаты инкубации.

Keywords: feeding, parent herd of cross ROSS 308, hatching eggs, morphological indicators of eggs, incubation results.

Одна из ключевых проблем индустрии птицеводства заключается в реализации генетического потенциала современных высокопродуктивных кроссов птицы и получении максимально возможной прибыли от производства за счет факторов кормления и, в частности, использования биологически активных добавок и препаратов, обладающих способностью активизировать естественные факторы резистентности, не вызывая нарушений в составе нормальной микрофлоры кишечника $[1,2,3]$.

Одними из таких препаратов являются пробиотики, которые стали активно использовать производители комбикормов и премиксов. В настоящее время накоплено достаточно много знаний о влиянии пробиотиков на микрофлору кишечника и обменные процессы в организме в сочетании с пребиотиками и другими препаратами $[4,5]$.

В связи с этим была поставлена задача изучить влияние нового препарата «ЭСИД-ПАК-4-УЭЙ» на яичную продуктивность и качественные показатели инкубационных яиц кур кросса РОС 308.

Комплексный пробиотический препарат «ЭСИД-ПАК-4-УЭЙ» (Оллтек, США) включает в себя уникальную комбинацию устойчивых к желчи молочнокислых бактерий Lactobacilluc asidophilus. Бактерии присутствуют в большом количестве, очень живучи и заключены в микрокапсулы.

Наряду с пробиотиками, препарат содержит ферменты (целлюлазу, протеазу и амилазу), набор важнейших биологических электролитов и органические кислоты.

Экспериментальные исследования по эффективности применения препарата «ЭСИД-ПАК-4-УЭЙ» проводились в условиях АО птицефабрика «РОСКАР» Ленинградской области.

Для проведения эксперимента были сформированы 2 группы кур родительского стада в возрасте 30 недель, по 70 голов в каждой. Опытная группа получала препарат дважды, с интервалом в 4 дня в течение 5 дней в дозировке 1г/л воды. В контрольной группе препарат не использовался. Продолжитель- 
ность опыта - 12 недель. Условия содержания и кормления птицы были одинаковыми.

В результате проведенных исследований установлено, что использование комплексного препарата «ЭСИД-ПАК-4-УЭЙ» положительно повлияло на яичную продуктивность кур родительского стада (таблица 1).

Таблица 1 - Продуктивность кур за период опыта

\begin{tabular}{|l|c|c|}
\hline \multirow{2}{*}{\multicolumn{1}{|c|}{ Изучаемые показатели }} & \multicolumn{2}{|c|}{ Группа } \\
\cline { 2 - 3 } & контрольная & опытная \\
\hline Среднее количество кур, голов & 70 & 70 \\
\hline Получено яиц: & & 4872 \\
\hline всего, шт. & 4788 & 69,6 \\
\hline на несушку, шт. & 68,4 & 82,7 \\
\hline Яйценоскость, \% & 81,4 & 66,07 \\
\hline Средняя масса яиц, г & 65,44 & 1,52 \\
\hline Затраты корма на 10 яиц, кг & 1,59 & 100 \\
\hline Сохранность, \% & 100 & \\
\hline
\end{tabular}

На всем протяжении учетного периода продуктивность кур опытной группы была выше, чем в контроле. В опытной группе получено на 84 яйца больше по сравнению с контролем. Яйценоскость возросла на 1,3\%, масса яиц увеличилась на 0,63 г, а затраты корма на получение 10 яиц снизились на 0,07 кг. Сохранность птицы обеих групп на всем протяжении опыта была высокой и составила $100 \%$.

Одним из основных факторов, определяющих результаты инкубации, жизнеспособность выведенного молодняка, продуктивность и племенную ценность несушек, является качество инкубационных яиц. Полученные данные свидетельствуют о том, что все показатели находились на уровне физиологической нормы, при этом испытуемый препарат положительно повлиял на качество инкубационных яиц (таблица 2).

Наблюдается увеличение массы яиц в опытной группе, в основном за счет увеличения массы желтка на 0,76 г ( $<0,05)$, показатель единиц ХАУ - на 0,44. Толщина скорлупы повысилась незначительно - всего на 3,0 мкм.

Таблица 2 - Морфологические показатели инкубационных яиц $(\mathrm{n}=10)$

\begin{tabular}{|l|c|c|}
\hline \multirow{2}{*}{\multicolumn{1}{|c|}{ Изучаемые показатели }} & \multicolumn{2}{|c|}{ Группа } \\
\cline { 2 - 3 } & контрольная & опытная \\
\hline Масса яиц, г & $65,73 \pm 0,71$ & $66,49 \pm 0,64$ \\
\hline Масса составных частей, г: белка & $38,06 \pm 0,47$ & $37,90 \pm 0,53$ \\
\hline желтка & $20,18 \pm 0,21$ & $20,94 \pm 0,27 *$ \\
\hline скорлупы & $7,49 \pm 0,19$ & $7,65 \pm 0,11$ \\
\hline Соотношение частей яйца, \%: & & $57,0 \pm 0,18$ \\
\hline белок & $57,9 \pm 0,21$ & \\
\hline
\end{tabular}




\begin{tabular}{|l|c|c|}
\hline желток & $30,7 \pm 0,14$ & $31,5 \pm 0,17$ \\
\hline скорлупа & $11,4 \pm 0,08$ & $11,5 \pm 0,06$ \\
\hline Отношение белок/желток & 1,91 & 1,84 \\
\hline Индекс формы, \% & $75,84 \pm 0,17$ & $75,32 \pm 0,15$ \\
\hline Индекс белка, \% & $8,37 \pm 0,09$ & $8,41 \pm 0,08$ \\
\hline Индекс желтка, \% & $44,19 \pm 0,32$ & $44,51 \pm 0,51$ \\
\hline Единицы ХАУ & $80,12 \pm 0,43$ & $80,56 \pm 0,39$ \\
\hline Упругая деформация, мкм & $21,57 \pm 0,29$ & $21,94 \pm 0,43$ \\
\hline Толщина скорлупы, мкм & $344,0 \pm 3,15$ & $347,0 \pm 2,81$ \\
\hline
\end{tabular}

Результаты инкубации яиц представлены в таблице 3.

Таблица 3 - Результаты инкубации яиц (возраст птицы 44 недели)

\begin{tabular}{|c|c|c|c|c|}
\hline \multirow{3}{*}{ Учитываемые показатели } & \multicolumn{4}{|c|}{ Группа } \\
\hline & \multicolumn{2}{|c|}{ контрольная } & \multicolumn{2}{|c|}{ опытная } \\
\hline & ШТ & $\%$ & ШТ & $\%$ \\
\hline Заложено яиц в инкубатор & 260 & 100 & 260 & 100 \\
\hline Оплодотворенность яиц & 236 & 92,69 & 239 & 93,46 \\
\hline \multicolumn{5}{|l|}{ Отходы инкубации, в т.ч.: } \\
\hline неоплодотворенные яйца & 24 & 9,13 & 21 & 8,08 \\
\hline «кровяное» кольцо & 13 & 5,00 & 10 & 3,85 \\
\hline замершие эмбрионы & 12 & 4,62 & 11 & 4,23 \\
\hline задохлики & 9 & 3,46 & 8 & 3,08 \\
\hline Выведено молодняка, гол & 202 & - & 210 & - \\
\hline Вывод здоровых цыплят, \% & - & 77,69 & - & 80,77 \\
\hline Выводимость яиц, \% & - & 85,59 & - & 87,87 \\
\hline
\end{tabular}

Вывод цыплят в опытной группе составил 80,77\%, что на 3,08\% выше, чем в контроле. Более высокий вывод цыплят в опытной группе был получен за счет повышения оплодотворенности яиц и снижения числа гибели эмбрионов в первые семь суток инкубации («кровяное» кольцо), это свидетельствует о положительном влиянии испытуемого препарата «ЭСИД-ПАК-4-УЭЙ» на усвоение питательных веществ и о биологически полноценном кормлении кур родительского стада в целом.

\section{Библиографический список}

1. Иванов, С.М. Качественные показатели инкубационных яиц при использовании в рационах птицы родительского стада тыквенного жмыха, обогащенного биодоступной формой йода / С.М. Иванов, З.Б. Комарова, Т.В. Берко, А.Н. Струк // Известия Нижневолжского агроуниверситетского комплекса: наука и высшее профессиональное образование. - Волгоград, 2016. - № 1(41). - С. 141148. 
2. Иванов, С.М. Влияние использования антистрессовых препаратов на яичную продуктивность кур-несушек / С.М. Иванов, Д.Н. Пилипенко, З.Б. Комарова // Инновационные технологии - основа модернизации отраслей производства и переработки сельскохозяйственной продукции: мат. междунар. науч.-практ. конф. 5-7 июня 2011. - Волгоград, 2011. - Ч. І. - С. 243-246.

3. Комарова, З.Б. Особенности физиологического состояния кур-несушек при использовании современных кормовых добавок / З.Б. Комарова, Д.Н. Пилипенко, С.М. Иванов // Известия Нижневолжского агроуниверситетского комплекса: наука и высшее профессиональное образование. - Волгоград, 2011. - № 3 (23). - C. 107-111.

4. Gorlov, Ivan Fiodorovich. Aspartate-complexed minerals in feeding broiler chickens / Ivan Fiodorovich Gorlov, Zoya Borisovna Komarova, Dmitriy Nikolaevich Nozhnik, Elena Yurievna Zlobina and Ekaterina Vladimirovna Karpenko // Research Journal of Pharmaceutical Biological and Chemical Sciences. 2016. - Vol. 7. - № 5. - P. 2890-2898.

5. Mazanko, M.S. Bacillus Probiotic Supplementations Improve Laying Performance, Egg Quality, Hatching of Laying Hens, and Sperm Quality of Roosters. / Mazanko M.S., I.F. Gorlov, E.V. Prazdnova, M.S. Makarenko, A.V. Usatov, A.B. Bren, V.A. Chistyakov, A.V. Tutelyan, Z.B. Komarova, N.I. Mosolova, D.N. Pilipenko, O.E. Krotova, A.N. Struk, A. Lin, M.L. Chikindas // Probiotics \& Antimicro. Prot. (2017). - Pp. 1-7. https://doi.org/10.1007/s12602-017-9369-4. 